\title{
Radular Force Performance of Stylommatophoran Gastropods (Mollusca) with Distinct Body Masses Reflect Diverging Feeding Patterns
}

WENCKE KRINGS ( $\square$ wencke.krings@uni-hamburg.de)

Universität Hamburg

CHARLOTTE NEUMANN

Universität Hamburg

MARCO T. NEIBER

Universität Hamburg

ALEXANDER KOVALEV

Christian-Albrechts-Universität zu Kiel

STANISLAV GORB

Christian-Albrechts-Universität zu Kiel

\section{Research Article}

Keywords: Force measurement, radula, feeding, biomechanics, trophic specialization, Eupulmonata

Posted Date: January 25th, 2021

DOI: https://doi.org/10.21203/rs.3.rs-151726/v1

License: (9) This work is licensed under a Creative Commons Attribution 4.0 International License.

Read Full License 


\section{Abstract}

The forces exerted by the animal's food processing structures are important parameters in studying trophic specializations to specific food spectra. Even though molluscs represent the second largest animal phylum, exhibiting an incredible biodiversity accompanied by the establishment of distinct ecological niches including the foraging on a variety of ingesta types, only few studies have been previously focused on the biomechanical performance of their feeding organs. To lay a keystone for future research in this direction, we investigated the in vivo forces exerted by the molluscan food gathering and processing structure, the radula, for five stylommatophoran species (Gastropoda). Radular forces were measured along two axes using force transducers which allowed us to correlate forces with the distinct phases of radular motion. The chosen species and individuals represent different body mass classes enabling the correction of forces measured for body mass. A radular force quotient, AFQ = force/bodymass ${ }^{0.67}$, of 4.3 could be determined which can be used further for the prediction of forces generated in Gastropoda. Additionally, some specimens were dissected and the radular musculature mass as well as the radular mass and dimensions were documented. Our results clearly depict the positive correlation between body mass, radular musculature mass, and exerted force. Additionally, it was clearly observed that the radular motion phases, exerting the highest forces during feeding, changed with regard to the ingesta size: all smaller gastropods rather approached the food by a horizontal, sawing-like radular motion leading to the consumption of rather small food particles, whereas larger gastropods rather pulled the ingesta in vertical direction by radula and jaw resulting in the tearing of larger pieces.

\section{Introduction}

The typical force exerted by feeding organs is a useful parameter indicating specializations to distinct food types, as it correlates with the food spectrum [see e.g. 1-7; for a review for stress-related puncture mechanics, see 8]. This topic had been studied quite intensively in vertebrates [for a summary of the relevant literature, see 6]: bite force analyses had been performed on mammals [e.g. 9-13], reptiles [e.g. 14-17], fish [e.g. 18-20], and birds [e.g. 21-22]. Even though the majority of animal species belong to the invertebrates, unfortunately fewer work focused on the forces exerted by their structures involved in either gathering or acquiring food due to the difficulties of an experimental set-up for studies of small structures. Exceptions and pioneers in this field are studies performed on representatives of Arthropoda: spiders, crustaceans, scorpions, and insects [23-29].

For molluscs, even though they represent the second specious animal group [e.g. 30] with around 80,000 recent species only within the Gastropoda [31], only few studies approached the forces exerted by their feeding organ, the radula. Since the species belonging to this animal phylum occupy almost any marine, freshwater or terrestrial environment and established extremely varied ecological niches [e.g. 32], accompanied with feeding on a wide range of food sources with various mechanical properties, mollusc trophic specializations are of very high interest for the evolutionary biology of this group. Their radula, one important molluscan autapomorphy and being interface between the organism and its ingesta (food, 
minerals), is highly diverse and offers an immense opportunity to study the structural adaptations enabling feeding on distinct ingesta types [see also 33].

The radula consists of a thin, chitinous membrane with rows of embedded, sometimes mineralized teeth which is supported by thick, underlying odontophoral cartilages and moved by numerous muscles of the buccal mass. The sometimes highly complex radular motion [see e.g. 34-39] brings the tooth cusps in contact with the ingesta leading to the tearing, cutting, and gathering of food.

As the teeth are involved as actual organism-ingesta interface, usually the shape of teeth or overall morphology of the radula had been examined and compared with the ingesta [e.g. 40-54; also examined for the tooth anchorage: 55]. In the context of phenotypic plasticity, different shapes of radular teeth as an answer to shifts of the ingesta have also been studied [45,56-66]. Sometimes these analyses are complemented by material property estimations of teeth [38,67-75]. Additionally, ingesta consumption, grazing activity, food choice experiments, and fecal analyses for diverse gastropod species have been investigated relating the gastropods with their preferred food, the abundance of food or other parameters of the microhabitat [76-82; for comprehensive reviews on diet of Heterobranchia, see 83-84].

The majority of previous studies have been focused on the radular teeth themselves, but the forces exerted by this organ or its biomechanical performance have unfortunately only been investigated in few papers devoted (1) to the feeding force calculations [85; or force calculations for radula-inspired gripping devices: 86], (2) to the experiments revealing the forces needed to remove algae [87-88], or (3) to the first in vivo experiment performed on a single mollusc species [89].

Here, to approach the topic of trophic specialization in molluscs and to lay a keystone for further studies, we investigated the in vivo radular forces, while foraging, for five different stylommatophoran species using force transducers following the protocol of [89]. These species were selected according to their similar radular type (isodont) and similar radular motion. As the species selected represent distinct body mass classes, the relationship between the body mass and radular force could be determined. We found that the stylommatophoran species perfectly follow the predictions for scaling of force and body mass as the radular force output scales to body mass ${ }^{0.67}$ with the quotient 4.25 and the Relative Force I scales to body mass ${ }^{-0.33}$ with the quotient 4.35 . Additionally, we performed buccal mass dissections in some specimens, succeeded by the determination of the radular (buccal mass) musculature and radular mass. Our results clearly depict that the measured radular forces correlate with the body mass and with the radular musculature mass. However, when corrected for the body mass smaller individuals generated relatively stronger forces. Regardless the maximum values of exerted forces, all gastropods were able to feed on the same food type and size, but smaller gastropods, to cope with the offered food, used a different radular motion pattern than the larger ones, which is reflected by the radular force measurements and corresponding video footage.

\section{Material And Methods}


For force measurements we have chosen five stylommatophoran species (Gastropoda: Heterobranchia), because all possess a similar radular type (isodont), have a similar radular foraging motion [for details on motion and radular type see e.g. 39,89-95], and represent distinct body mass classes (Fig. 1): immature (one juvenile stage) and mature Lissachatina fulica (Bowdich, 1822), mature Cepaea nemoralis (Linnaeus, 1758), mature Cepaea hortensis (Müller, 1774), mature Helix pomatia Linnaeus, 1758, and mature Arion vulgaris Moquin-Tandon, 1855. Overall, 24 individuals were used for feeding experiments. Individuals of $L$. fulica were received from private animal breeders, the other species were collected in Hamburg, Germany, in May 2020. Species identification is based on the relevant literature.

The selected gastropods species were assigned to different body mass classes (large sized animals $=$ mature $L$. fulica [ $\mathrm{N}=5$ individuals], medium sized animals $=H$. pomatia and immature $L$. fulica $[\mathrm{N}=10$ individuals], small sized animals $=C$. nemoralis, $C$. hortensis, $A$. vulgaris $[\mathrm{N}=9$ individuals] $)$ and cohorts (mature $L$. fulica [ $\mathrm{N}=5$ individuals], immature $L$. fulica [ $\mathrm{N}=9$ individuals], mature H. pomatia $[\mathrm{N}=1$ individual], mature $C$. nemoralis [ $\mathrm{N}=2$ individuals], mature $C$. hortensis $[\mathrm{N}=1$ individual], mature $A$. vulgaris [ $\mathrm{N}=6$ individuals]). Before each experiment, individuals were weighed (body mass with shell) (see Supplementary Table 1).

Forces exerted by the radula (= Absolute Forces) were measured following the protocol of [89]. Snails were placed on an acrylic platform with a small hole of $4 \mathrm{~mm}$ diameter. The platform was attached to a laboratory jack so that the height could be adjusted. Food stripes (sliced to pieces of 3 [width] $\times 2$ [length] $x 20$ or 40 [height] $\mathrm{mm}$; either carrot or fresh strawberry depending on the specific preference of the species) were glued to a needle, which was mounted onto a force transducer FORT-10 (World Precision Instruments, Sarasota, FL, USA) and stuck through the hole so that the snail could feed on it, but without the involvement of the foot (Fig. 2). A $1000 \mathrm{~g}$ sensor was used for mature L. fulica, for all other individuals a $25 \mathrm{~g}$ sensor was used. Forces could only be measured in either vertical or horizontal direction not in both simultaneously, thus the experimental set-up was remodeled to receive data for both directions [see also 89]. The force transducers were connected to an amplifier (Biopac System, Inc., CA, USA) and a computer-based data acquisition and processing system (AcqKnowledge ${ }^{\mathrm{TM}}$, Biopac Systems, Inc., v.3.7.0.0, World Precision Instruments, Sarasota, FL, USA). Not all force peaks were analyzed in AcqKnowledge $^{\mathrm{TM}}$ due to the large sample size, but about 30 maximal and minimal force peaks were evaluated per feeding unit (for the detailed quantity of evaluated force peaks per species, individual, and direction see Supplementary Table 1), overall 4407. Forces were corrected for mean body mass with shell to receive Relative Force I (force/ mean body mass with shell, $\mathrm{mN} / \mathrm{g}$ ). Mean and standard deviations were calculated and statistical analysis was performed with the program JMP® Pro 14 (SAS Institute Inc., Cary, NC, 1989-2007) comparing the exerted forces between (a) the distinct body mass classes, (b) the cohorts, (c) the directions, (d) the individual animals. A Shapiro-Wilk test, followed by a one-way ANOVA, and a Tukey-Kramer test with connecting letters report identifying homogenous groups was carried out. For linear regression of Absolute Force and Relative Force I versus whole body mass mean values were displayed on logarithmic axes with excel 2013 (Microsoft Corporation, Redmond, USA) and 
trend lines were determined. A radular force quotient, $A F Q=$ absoluteforce $/$ bodymass $^{0.67}$, and a relative force quotient, $\mathrm{RFQ}=$ relativeforcel/bodymass ${ }^{-0.33}$, were determined.

Detailed radular motion, while feeding on a flat surface was documented with a Keyence VHX-500 digital microscope (KEYENCE, Neu-Isenburg, Germany) by placing the individual on an acrylic platform, providing flour paste as food [see also 39,89]. The behavior, while foraging on a carrot, was documented with an iPad Pro (11 zoll; Apple Inc., Cupertino, USA) equipped with a 12 megapixel wide angle lens with 30 frames per second (see Supplementary Videos 1 and 2). Videos were cut and cropped with Adobe Premiere Pro 2020 (Adobe Inc., San Jose, USA).

Some animals (see Supplementary Fig. 8) were either killed by brief boiling (shelled animals) or by placing them in carbonated water (slugs). They were preserved in $70 \% \mathrm{EtOH}$ and inventoried in the malacological collection of the Zoological Museum Hamburg $(\mathrm{ZMH})$ of the Centrum für Naturkunde (CeNak); Cepaea nemoralis: ZMH 154748/8, Helix pomatia: ZMH 154749/1, Lissachatina fulica: ZMH 154751/2, Cepaea hortensis. ZMH 154754/1, Arion vulgaris. ZMH 154747/12.

The shells of dead specimens were removed and the soft parts were weighed to receive body mass without shell. Forces were corrected for body mass without shell to receive Relative Force II (force/ body mass without shell, $\mathrm{mN} / \mathrm{g}$ ). To estimate the mass of the entire buccal mass (BRJ), the radula and jaw $(\mathrm{RJ})$, and the buccal mass musculature (B) these specimens were dissected which was documented with a Keyence VHX-500 digital microscope (KEYENCE, Neu-Isenburg, Germany). The BRJ was first extracted, freed from surrounding tissue (see Supplementary Fig. 7) and weighed in wet condition with an accuracy weighing machine (Sartorius Cubis, MSE, Sartorius AG, Göttingen, Germany). Subsequently the radula and jaw (RJ) were separated from the buccal mass musculature (B) manually; RJ and B were weighed in wet condition. $B$ and RJ were then dried for one week and weighed again to obtain data on dry mass. Forces were corrected for dry B to receive Relative Force III (force/ dry B mass, mN/mg) and for dry RJ to receive Relative Force IV (force/ dry RJ mass, $\mathrm{mN} / \mathrm{mg}$ ).

For scanning electron microscope (SEM) images radulae and jaws were rewetted and cleaned with proteinase $\mathrm{K}$ digesting food particles according to the protocol of [96], followed by a short ultrasonic bath. Structures were mounted on SEM stubs, coated with palladium and visualized with a Zeiss LEO 1525 (One Zeiss Drive, Thornwood, USA). Radular length, width, and area could be calculated. Forces were corrected for radular area to receive Relative Force $\mathrm{V}$ (force / radular area, $\mathrm{mN} / \mathrm{mm}^{2}$ ).

\section{Results}

\section{Radula and its teeth}

All analyzed species possess an isodont radula (Supplementary Figs. 3-6). Lissachatina fulica displays $\sim 84$ teeth per row (no central tooth, 16 lateral and 26 marginal teeth on each side), Helix pomatia 87 teeth per row (one central tooth, 23 lateral and 20 marginal teeth on each side), Arion vulgaris 75 teeth 
per row (one central tooth, 16 lateral and 21 marginal teeth on each side), Cepaea nemoralis and $C$. hortensis 51 teeth per row (one central tooth, 12 lateral and 13 marginal teeth on each side). The jaws of all species are thick, curved, chitinous plates with ribs (i.e. odontognathous).

\section{Radular motion}

Video footage reveals the radular motion and feeding behaviour (see Supplementary Videos 1 and 2). While feeding, the radula is pushed simultaneously in ventral (vertical down) and anterior (horizontal anterior) direction, before the organ is finally pulled in dorsal (vertical up) and posterior (horizontal posterior) direction and the mouth is closed. With the first part of the motion the radula loosens food items from the ground and collects particles, which are transported into the mouth opening in the latter phase of the feeding action. When feeding on larger ingesta (e.g. a piece of carrot; see Supplementary Video 1), the anterior part of the radula and the jaw act in concert as counter bearing squeezing and pulling the ingesta. When comparing the feeding behaviours of different individuals we can see that the large sized individuals can completely enclose the carrot piece with their lips, resulting in a dragging on the carrot in vertical direction, tearing large pieces, whereas the small and medium sized individuals are not comfortable with this due to the small dimension of their mouth. These individuals usually nibble on edges of the item, cutting and slicing smaller pieces in rather horizontal direction employing their radula like a saw, sometimes involving additionally the foot as a clamp (Supplementary Video 2). All gastropods were able to consume the food items offered, but small sized individuals needed to invest approximately $800-900 \%$ and medium sized ones $400-500 \%$ more time to consume the similar sized food items than large sized gastropods.

\section{Force measurements}

Overall, 4407 individual force peaks were evaluated (for evaluated quantity of peaks per species, individual, and direction see Supplementary Table 1). For Absolute Forces exerted by the body mass classes see Fig. 3; for Absolute Forces exerted by the cohorts see Fig. 4 and Supplementary Table 2; for the Absolute Forces of individual gastropods see Supplementary Figs. 1, 2, and Supplementary Tables 3 , 4.

Comparing the Absolute Forces regardless the direction between the three body mass classes of animals (Fig. 3A) we detect significant differences ( $<<0.0001$, F-ratio: 336.03, df: 2). Large sized individuals are capable of exerting highest forces (mean \pm standard deviation; $73.96 \pm 62.49 \mathrm{mN} ; \mathrm{N}=1025$ evaluated force peaks), followed by the medium sized ( $41.44 \pm 49.18 \mathrm{mN} ; \mathrm{N}=2581)$, and finally small sized individuals ( $14.46 \pm 24.49 \mathrm{mN} ; \mathrm{N}=801)$. When comparing the Relative Force I regardless the direction between the three body mass classes of animals (Fig. 3B) we detect significant differences between groups ( $<<0.0001$; F-ratio: $346.10 ; \mathrm{df}: 2$ ). Here, small sized individuals exhibited the highest Relative Force I $(6.01 \pm 8.40 \mathrm{mN} / \mathrm{g})$, followed by the medium sized $(2.47 \pm 2.94 \mathrm{mN} / \mathrm{g})$, and finally large sized animals $(0.84 \pm 0.74 \mathrm{mN} / \mathrm{g})$. 
The Absolute Force (regardless the direction) quotient, $\mathrm{AFQ}=$ absoluteforce/bodymass $^{0.67}$, is found to be 4.25 and the Relative Force I (regardless the direction) quotient, RFQ = relativeforcel/bodymass ${ }^{-0.33}, 4.35$ (see Fig. 5).

Absolut Forces assorted to direction (Fig. 3C) also differed significantly between body mass classes (for horizontal anterior: $\mathrm{p}<0.0001$, F-ratio: 240.09, df: 2; horizontal posterior: $\mathrm{p}<0.0001$, F-ratio: 104.69, df: 2; vertical down: $p<0.0001$, F-ratio: 393.05, df: 2; vertical up: $p<0.0001$, F-ratio: 544.38, df: 2). For horizontal anterior direction, the highest forces were, however, exerted by the medium sized class $(-82.22 \pm 55.10$ $\mathrm{mN} ; \mathrm{N}=617)$, followed by the large $(-26.97 \pm 2.91 \mathrm{mN} ; \mathrm{N}=223)$, and finally small sized gastropods $(-15.34 \pm 7.87 \mathrm{mN} ; \mathrm{N}=180)$. For horizontal posterior direction, the highest forces were again exerted by the medium sized class $(74.52 \pm 49.76 \mathrm{mN} ; \mathrm{N}=536)$, followed by the small sized gastropods (39.56 \pm $35.37 \mathrm{mN} ; \mathrm{N}=211)$, and finally large $(38.82 \pm 19.49 \mathrm{mN} ; \mathrm{N}=323)$. In the direction vertical down, the large sized gastropods showed highest forces $(-22.77 \pm 17.79 \mathrm{mN} ; \mathrm{N}=107)$, followed by the medium $(-3.94 \pm$ $2.30 \mathrm{mN} ; \mathrm{N}=440)$, and finally small gastropods $(-0.86 \pm 0.44 \mathrm{mN} ; \mathrm{N}=210)$. The same is found for vertical up: large gastropods ( $147.35 \pm 41.35 \mathrm{mN} ; \mathrm{N}=372)$, medium $(14.72 \pm 10.40 \mathrm{mN} ; \mathrm{N}=988)$, and finally small ones (1.48 $\pm 0.72 \mathrm{mN} ; \mathrm{N}=200)$. When comparing the Relative Force I assorted to direction (Fig. 3D) we again detect significant differences between body mass classes (for horizontal anterior: $p<0.0001$, Fratio: 181.52, df: 2; horizontal posterior: $p<0.0001$, F-ratio: 620.28 , df: 2; vertical down: $p<0.0001$, F-ratio: 109.90, df: 2; vertical up: $p<0.0001$, F-ratio: 233.52, df: 2). Here, for horizontal anterior direction, the highest Relative Force I was exerted by the small sized gastropods $(9.26 \pm 9.08 \mathrm{mN} / \mathrm{g})$, followed by the medium $(4.98 \pm 3.59 \mathrm{mN} / \mathrm{g})$, and finally large ones $(0.30 \pm 0.13 \mathrm{mN} / \mathrm{g})$. For horizontal posterior direction, the highest Relative Force I was again exerted by the small $(13.63 \pm 8.67 \mathrm{mN} / \mathrm{g})$, followed by the medium $(4.28 \pm 2.65 \mathrm{mN} / \mathrm{g})$, and finally large sized class individuals $(0.43 \pm 0.20 \mathrm{mN} / \mathrm{g})$. In the direction vertical down, the small sized gastropods showed highest Relative Force I $(0.50 \pm 0.28 \mathrm{mN} / \mathrm{g})$, followed by the large $(0.25 \pm 0.21 \mathrm{mN} / \mathrm{g})$, and finally medium gastropods $(0.24 \pm 0.17 \mathrm{mN} / \mathrm{g})$. For vertical up direction, the large gastropods $(1.69 \pm 0.54 \mathrm{mN} / \mathrm{g})$ exerted highest Relative Force I, followed by the medium $(0.92 \pm 0.65$ $\mathrm{mN} / \mathrm{g})$, and finally small ones $(0.85 \pm 0.51 \mathrm{mN} / \mathrm{g})$.

When comparing Absolut Forces regardless the direction between cohorts (Fig. 4A) we found significant differences ( $p<0.0001$, F-ratio: 114.24, df: 5). Highest forces were exerted by mature $L$. fulica $(73.96 \pm$ $62.49 \mathrm{mN} ; \mathrm{N}=1025)$, followed by $H$. pomatia $(55.98 \pm 65.25 \mathrm{mN} ; \mathrm{N}=270)$, immature L. fulica (39.73 \pm $46.67 \mathrm{mN} ; \mathrm{N}=2311), C$. nemoralis $(23.01 \pm 35.08 \mathrm{mN} ; \mathrm{N}=316)$, A. vulgaris $(10.25 \pm 11.79 \mathrm{mN} ; \mathrm{N}=325)$, and finally $C$. hortensis $(6.10 \pm 6.60 \mathrm{~N}=160)$. When comparing Relative Force I regardless the direction between cohorts (Fig. 4B) we found significant differences ( $p<0.0001$, F-ratio: 198.21, df: 5). Highest Relative Force I was exerted by $C$. hortensis $(9.43 \pm 10.17 \mathrm{mN} / \mathrm{g})$, followed by $C$. nemoralis $(6.85 \pm 9.99$ $\mathrm{mN} / \mathrm{g})$, A. vulgaris $(3.52 \pm 3.72 \mathrm{mN} / \mathrm{g})$, immature L. fulica $(2.59 \pm 3.03 \mathrm{mN} / \mathrm{g})$, H. pomatia $(1.47 \pm 1.72$ $\mathrm{mN} / \mathrm{g})$, and finally mature $L$. fulica $(0.84 \pm 0.74 \mathrm{mN} / \mathrm{g})$.

Comparing the Absolut Forces assorted to direction between cohorts (Fig. 4B) we found significant differences (for horizontal anterior: $p<0.0001$, F-ratio: 96.17 , df: 5; horizontal posterior: $p<0.0001$, F-ratio: 82.07, df: 5; vertical down: $p<0.0001$, F-ratio: 156.98, df: 5; vertical up: $p<0.0001$, F-ratio: 2176.63, df: 5). 
For horizontal anterior direction, the highest forces were exerted by H. pomatia, followed by the immature L. fulica, mature L. fulica, $A$. vulgaris, $C$. hortensis, and finally $C$. nemoralis (for values and connecting letters see Supplementary Table 2). For horizontal posterior direction, the highest forces were exerted by H. pomatia, followed by $C$. nemoralis, the immature L. fulica, mature L. fulica, A. vulgaris, and finally $C$. hortensis. For vertical down direction, the highest forces were exerted by mature $L$. fulica, followed by $H$. pomatia, the immature $L$. fulica, $A$. vulgaris, $C$. nemoralis, and finally $C$. hortensis. For vertical up direction, the highest forces were exerted by mature $L$. fulica, followed by the immature $L$. fulica, $H$. pomatia, $C$. nemoralis, $A$. vulgaris, and finally $C$. hortensis. When comparing the Relative Force I assorted to direction between cohorts (Fig. 4C) we found significant differences (for horizontal anterior: $p<0.0001$, F-ratio: 428.67, df: 5; horizontal posterior: $p<0.0001$, F-ratio: 728.85 , df: 5; vertical down: $p<0.0001$, F-ratio: 139.78, df: 5; vertical up: $p<0.0001$, F-ratio: 135.26, df: 5). For horizontal anterior, the highest Relative Force I was exerted by $C$. hortensis, followed by $A$. vulgaris, the immature $L$. fulica, $C$. nemoralis, $H$. pomatia, and finally mature $L$. fulica (for values and connecting letters see Supplementary Table 2 ). For horizontal posterior direction, the highest Relative Force I was exerted by $C$. nemoralis, followed by $C$. hortensis, $A$. vulgaris, the immature $L$. fulica, H. pomatia, and finally mature $L$. fulica. For vertical down direction, the highest Relative Force I was exerted by $C$. hortensis, followed by $A$. vulgaris, the immature $L$. fulica, mature $L$. fulica, $C$. nemoralis, and finally $H$. pomatia. For vertical up direction, the highest Relative Force I was exerted by mature $L$. fulica, followed by $C$. hortensis, the immature $L$. fulica, $A$. vulgaris, $C$. nemoralis, and finally $H$. pomatia.

\section{Masses of body, radula, buccal mass musculature, and radular sizes}

Highest whole body mass (see Supplementary Table 1 ) was measured for $L$. fulica mature 1 , followed by H. pomatia, L. fulica immature 9, C. nemoralis 1 , A. vulgaris $2,4,5, C$. nemoralis $2, A$. vulgaris 1 , and finally $C$. hortensis.

Overall, we found that the body mass (with and without shell) relates in proportion to the masses of the whole buccal mass (wet; BRJ), the radular musculature (buccal mass musculature, wet and dry; B), and the radula and jaw (wet and dry; RJ). When individuals were heavier, they usually possessed higher muscle mass, a heavier radula and jaw (see Supplementary Fig. 8 and Supplementary Table 6). Exceptions were: $L$. fulica immature 9 (18 g body mass and $205.01 \mathrm{mg}$ whole buccal mass) and $H$. pomatia (38 g body mass and $163.30 \mathrm{mg}$ whole buccal mass), C. nemoralis 1 (3.60 g body mass and $27.20 \mathrm{mg}$ whole buccal mass), and $A$. vulgaris 2 ( $3.50 \mathrm{~g}$ body mass and $56.66 \mathrm{mg}$ whole buccal mass). Comparing mature (mature $1: 78.00 \mathrm{~g}$ body mass and $286.80 \mathrm{mg} \mathrm{BRJ}$ ) and immature $L$. fulica (immature 9: $18.00 \mathrm{~g}$ body mass and $205.01 \mathrm{mg} \mathrm{BRJ}$ ) we found that the body mass increases for the factor $\sim 4$ and BRJ increases for the factor 1.4 .

We found that smaller gastropods are mostly capable of exerting higher forces per radular muscle mass (see Supplementary Fig. 9 and Supplementary Table 6). Cepaea hortensis exerted the highest force per radular musculature mass, followed by $C$. nemoralis $1, A$. vulgaris 4 and $5, C$. nemoralis $2, H$. pomatia, $L$. 
fulica mature 1, L. fulica immature 9, and finally A. vulgaris 1 and 2 . The same sequence was also found for force per body mass without shell. With the exception of $A$. vulgaris 4 and 5 , exerting the highest forces per radula and jaw mass, we detected the same order for this parameter.

The radular length and width (see Supplementary Fig. 8 and Supplementary Table 5) do not consistently correlate with body mass, the highest radular width was measured for $L$. fulica mature 1 (width in $\mu \mathrm{m}$ : 4933; length in $\mu \mathrm{m}$ : 5178), followed by $A$. vulgaris 5 (4725; 2156) L. fulica immature $9(3945 ; 8165), H$. pomatia $(3023 ; 9077)$, A. vulgaris $4(2597 ; 4947)$ A. vulgaris 1 (1999; 3765), A. vulgaris $2(1869 ; 5701), C$. nemoralis $2(1780 ; 3492), C$. nemoralis 1 (1558; 4906), and finally $C$. hortensis $(1034 ; 4351)$. Both gastropods with the largest width possessed shorter radulae than all other specimens. L. fulica immature 9 possessed the largest radular area $\left(32.21 \mathrm{~mm}^{2}\right)$, followed by H. pomatia $\left(27.44 \mathrm{~mm}^{2}\right)$, L. fulica mature $1\left(25.54 \mathrm{~mm}^{2}\right)$, A. vulgaris $4\left(12.85 \mathrm{~mm}^{2}\right)$, A. vulgaris $2\left(10.66 \mathrm{~mm}^{2}\right), A$. vulgaris $5\left(10.19 \mathrm{~mm}^{2}\right), C$. nemoralis $1\left(7.64 \mathrm{~mm}^{2}\right)$, A. vulgaris $1\left(7.52 \mathrm{~mm}^{2}\right), C$. nemoralis $2\left(6.22 \mathrm{~mm}^{2}\right)$, and finally $C$. hortensis $\left(4.50 \mathrm{~mm}^{2}\right)$. The radular area again did not consistently correlate with the whole body mass.

\section{Discussion}

Force output is often referred to as proportional to muscle mass ${ }^{0.67}$, the muscle cross-sectional area [e.g. 97-98], or to body mass ${ }^{0.67}$ [e.g. 99] whereas the forces, corrected for body mass (force/mass), are referred to be proportional to body mass ${ }^{-0.33}$ [e.g. 99]. The stylommatophoran species examined here perfectly follow the predictions for scaling of force and body mass. Following previous studies [27, 100] we here experimentally determined a radular force quotient $\mathrm{AFQ}, \mathrm{AFQ}=$ force/bodymass ${ }^{0.67}$, of 4.25 and a relative force quotient RFQ, RFQ = relativeforcel/bodymass ${ }^{-0.33}$ of 4.35 which can be further used for predictions of forces in Gastropoda.

The here measured absolute feeding forces for Helix pomatia are in a similar range as to those documented by [89] for Cornu aspersum, both gastropod groups have comparable body mass. We detected that gastropods with a higher body mass and a larger body size were capable of exerting higher radular forces, which is not surprising. However, the relationship between forces generated by the feeding organ and body size is well documented for vertebrates, but not for molluscs. When forces are corrected for body size or mass, ecological adaptations related with this parameter became more pronounced [e.g. 4-5,9,12,21; for hypotheses about body size related evolution of bite force, see also 101-102]. When determining the radular force per body mass (termed Relative Force I), we see that smaller gastropods were capable of exerting the highest forces, followed by the medium, and finally large ones, similar to e.g. Carnivora [12]. This is also not surprising, because of different scaling of body mass and cross-sectional area of muscles [103-104]. Usually, specimens exhibiting a higher body mass also possess a proportionally higher mass of buccal mass [correlation between buccal mass size and gastropod body size was also previously described by 56]. However, the immature and adult Lissachatina fulica, exhibiting strong differences in body mass and size, but having almost similar buccal mass sizes and masses, are an exception to this rule. In most experiments mature $L$. fulica exerted higher radular forces 
than the immature gastropods, but some measurements (outliers) revealed that immature L. fulica are also capable of generating the same feeding forces as the mature ones. This could be an indication that the ingesta type does not change during ontogeny; however, this aspect awaits further investigation. However, our analyses of Relative Force I (Fig. 4) reveal distinct radular force patterns for cohorts, both Cepaea species have a wide range of exerted forces, followed by Arion, Lissachatina immature, and finally, with the smallest range, Lissachatina mature. This could be an indication that Cepaea potentially feeds naturally on a broader food spectrum whereas Lissachatina is more restricted, but this also awaits further investigations.

In past studies, it has been shown that the forces generated usually correlate with the muscle mass, muscle size, or muscle diameter [for vertebrates: e.g. 13,21,-106; for invertebrates: 107]. This is congruent to the here observed patterns in gastropods. However, for precise interpretation of the relationship between buccal mass size and the mass of the radular muscles (buccal mass musculature) precise knowledge about the functional role of each feeding muscle is important, which is not the case for these taxa studied here. There are some detailed studies analyzing the in vivo buccal mass movement and buccal mass muscle function in Aplysia [91-92, 94, 108]. However as Aplysia belongs to the Opisthobranchia and is not closely related to the taxa studied here the function of the buccal mass muscles for the stylommatophoran taxa studied here cannot be assigned yet. However, to deeply understand the relationship between measured radular forces involved in specific radular motions, the function of each muscle, their work in concert, as well as the muscle and fiber size, length, or diameter need to be investigated. As there are many different parameters that relate with feeding force [for vertebrates: e.g. the skull geometry and size: 4,15,22,109-111; or muscular development: 106], it is very difficult to produce reliable models for molluscs due to the lack of solid experimental data. Additionally, studies on invertebrates reveal that muscle stress varies considerably depending on the muscle [112114]. This could also be the case for molluscs as the forces exerted per radular muscular mass differ extremely between the analyzed stylommatophoran individuals (see Supplementary Fig. 9 and Supplementary Table 6). This again shows that pure anatomy-based studies on the muscle systems of invertebrates do not necessarily provide data on physiology [see also 29].

Our results clearly indicate that larger and heavier animals exerted higher forces in the vertical directions, whereas medium and small individuals exerted higher forces in horizontal directions. This is additionally supported by the analyses of the video footage showing that larger animals rather pull with radula and jaw, whereas smaller individuals use their radular often like a saw in anterior-posterior direction when approaching the food item (see Supplementary Video 1 and 2). This shift in feeding behavior seems to depend on the ingesta size in relation to the mouth opening size. Smaller and medium sized gastropods even though capable of embracing the whole item with the lip - seem to prefer this alternative feeding pattern. An ingesta-depending shift in feeding pattern, i.e. dynamics of swallowing, had been documented for other gastropod taxa when altering parameters of the ingesta [108], e.g. its hardness [115], its load and width [116], or its size [117-119]. Additionally, gastropods of different sizes have been found to feed on different ingesta types, possibly correlating with ontogenetic size changes of the mouthparts [120]. 
As already stated above, heavier gastropods were usually capable of exerting higher radular forces than smaller ones (except for immature and adult $L$. fulica). This indicates that larger gastropods might forage on a broader spectrum of ingesta, as it had been previously described for turtles [110]. However, the smaller individuals were able to exert higher forces per body mass and additionally show a distinct radular motion pattern resulting in a distinct feeding pattern. All experiments resulted in the consumption of the ingesta offered, but smaller gastropods invested more time. This effect had also been observed for lizards [3] and should be further investigated for Mollusca. Thus, we can conclude that in studies of feeding forces of gastropods with a similar radular type, teeth, and radular motion, adaptations to ingesta might only been detected by studying feeding efficiency and invested time. We hope that in the future more biomechanical, physiological and functional morphological studies will approach the topic of trophic specialization in molluscs using feeding force experiments on molluscs possessing different radular types and feeding on more distinct ingesta types.

\section{Declarations}

\section{Authors' contribution}

WK and SG initiated the project, discussed the data analysed, performed statistical analyses. CN performed experiments, analysed data, and contributed to earlier versions of the manuscript. SG provided experimental design and contributed to the biomechanical aspects of the manuscript. MTN performed species identification. AK contributed to data analysis. All authors contributed to and approved the final manuscript for publication.

\section{Acknowledgements}

We would like to thank Renate Walter from the Zoological Institute of the Universität Hamburg for support on the SEM, Thomas M. Kaiser from the CeNak of the Universität Hamburg for discussing results. We are grateful for the helpful comments of the anonymous reviewers.

\section{References}

1. Kiltie, R. Bite force as a basis for niche differentiation between rain forest peccaries (Tayassu tajacu and T. pecari). Biotropica. 14 (3), 188-195 (1982).

2. Herrel, A., Spithoven, L., Van Damme, R. \& De Vree, F. Sexual dimorphism of head size in Gallotia galloti: testing the niche divergence hypothesis by functional analyses. Funct. Ecol. 13, 289-297 (1999).

3. Verwaijen, D., Van Damme, R. \& Herrel, A. Relationships between head size, bite force, prey handling efficiency and diet in two sympatric lacertid lizards. Funct. Ecol. 16 (6), 842-850 (2002).

4. Erickson, G. M., Lappin, A. K. \& Viet, K. A. The ontogeny of bite-force performance in American alligator (Alligator mississippiensis). J. Zool. 260 (6), 317-327 (2003). 
5. Sustaita, D. \& Hertel, F. 2010. In vivo bite and grip forces, morphology and prey killing behavior of North American accipiters (Accipitridae) and falcons (Falconidae). J. Exp. Biol. 213, 2617-2628.

6. Lappin, A. K. \& Jones, M. H. E. Reliable quantification of bite-force performance requires use of appropriate biting substrate and standardization of bite out-lever. J. Exp. Biol. 217, 4303-4312 (2014).

7. Moretti, M. et al. Handbook of protocols for standardized measurement of terrestrial invertebrate functional traits. Funct. Ecol. 31, 558-567 (2016).

8. Anderson, P. S. L. Making a point: shared mechanics underlying the diversity of biological puncture. J. Exp. Biol. 221, jeb187294 (2018).

9. Aguirre, L. F., Herrel, A., van Damme, R. \& Matthysen, E. 2002. Ecomorphological analysis of trophic niche partitioning in a tropical savannah bat community. Proc. Biol. Sci. 269, 1271-1278.

10. Wroe, S., McHenry, C. \& Thomason, J. 2005. Bite club: comparative bite force in big biting mammals and the prediction of predatory behaviour in fossil taxa. Proc. Biol. Sci. 272, 619-625.

11. Christiansen, P. Evolutionary implications of bite mechanics and feeding ecology in bears. J. Zool. Lond. 272, 423-443 (2007).

12. Christiansen, P. \& Wroe, S. Bite forces and evolutionary adaptations to feeding ecology in carnivores. Ecology. 88 (2), 347-358 (2007).

13. Herrel, A., De Smet, A., Aguirre, L. F. \& Aerts, P. Morphological and mechanical determinants of bite force in bats: do muscles matter? J. Exp. Biol. 211, 86-91 (2008).

14. Herrel, A., O’Reilly, J. C. \& Richmond, A. M. Evolution of bite performance in turtles. J. Evol. Biol. 15, 1083-1094 (2002).

15. Herrel, A. \& O’Reilly, J. C. Ontogenetic scaling of bite force in lizards and turtles. Physiol. Biochem. Zool. 79 (1), 31-42 (2006).

16. Vervust, B., Brecko, J. \& Herrel, A. Temperature effects on snapping performance in the common snapper Chelydra serpentine (Reptilia, Testudines). J. Exp. Zool. A. 315, 41-47 (2011).

17. Kaliontzopoulou, A., Adams, D. C., Van der Meijden, A., Perera, A. \& Carretero, M. A. Relationships between head morphology, bite performance and ecology in two species of Podarcis wall lizards. Evol. Ecol. 26, 825-845 (2012).

18. Huber, D. R., Eason, T. G., Hueter, R. E. \& Motta, P. J. Analysis of the bite force and mechanical design of the feeding mechanism of the durophagous horn shark Heterodontus francisci. J. Exp. Biol. 208, 3553-3571 (2005).

19. Huber, D. R., Weggelaar, C. L. \& Motta, P. J. Scaling of bite force in the blacktip shark Carcharhinus limbatus. Zoology. 109, 109-119 (2006).

20. Huber, D. R., Dean, M. N. \& Summers, A. P. Hard prey, soft jaws and the ontogeny of feeding mechanics in the spotted ratfish Hydrolagus colliei. J. R. Soc. Interface. 5, 941-952 (2008).

21. Van der Meij, M. A. A. \& Bout, R. G. Scaling of jaw muscle size and maximal bite force in finches. J. Exp. Biol. 207, 2745-2753 (2004). 
22. Herrel, A., Podos, J., Huber, S. K. \& Hendry, A. P. Bite performance and morphology in a population of Darwin's finches: implications for the evolution of beak shape. Funct. Ecol. 19, 43-48 (2005).

23. Wheater, C. P. \& Evans, M. E. G. The mandibular forces and pressures of some predacious Coleoptera. J. Insect. Physiol. 35, 815-820 (1989).

24. Taylor, G. M. 2000. Maximum force production: why are crabs so strong? Proc. Biol. Sci. 267, 14751480.

25. Claussen, D. L., Gerald, G. W., Kotcher, J. E. \& Miskell, C. A. Pinching forces in crayfish and fiddler crabs, and comparisons with the closing forces of other animals. J. Comp. Physiol. B178, 333-342 (2008).

26. Van der Meijden, A., Herrel, A. \& Summers, A. Comparison of chela size and pincer force in scorpions; getting a first grip. J. Zool. 280, 319-325 (2010).

27. Van der Meijden, A., Langer, F., Boistel, R., Vagovic, P. \& Heethoff, M. Functional morphology and bite performance of raptorial chelicerae of camel spiders (Solifugae). J. Exp. Biol. 215, 3411-3418 (2012).

28. Goyens, J., Dirckx, J., Dierick, M., Van Hoorebeke, L. \& Aerts, P. Biomechanical determinants of bite force dimorphism in Cyclommatus metallifer stag beetles. J. Exp. Biol. 217, 1065-1071 (2014).

29. Weihmann, T., Reinhardt, L., Weissing, K., Siebert, T. \& Wipfler, B. Fast and powerful: Biomechanics and bite forces of the mandibles in the American cockroach Periplaneta Americana. PLOS ONE. 10 (11), (2015). e0141226

30. Chapman, A. D. 2009. Numbers of living species in Australia and the world. 2nd edition. Australian Biodiversity Information Services, Toowoomba, Australia.

31. Bouchet, P. et al. 2005. Classification and nomenclator of gastropod families. Malacologia 47(1-2). ConchBooks: Hackenheim, Germany.

32. Wanninger, A. \& Wollesen, T. The evolution of molluscs. Biol. Rev. 94, 102-115 (2019).

33. Padilla, D. K. Form and function of radular teeth of herbivorous molluscs: focus on the future. Am. Malacol. Bull. 18 (1-2), 163-168 (2003).

34. Ankel, W. E. Erwerb und Aufnahme der Nahrung bei den Gastropoden. Verh. Dtsch. Zool. Ges., Zoologischer Anzeiger. 11, 223-295 (1938).

35. Eigenbrodt, H. Untersuchungen über die Funktion der Radula einiger Schnecken. Z. Morphol. Oekol. Tiere. 37, 735-791 (1941).

36. Crampton, D. Functional anatomy of the buccal apparatus of Onchidoris bilamellata (Mollusca: Opisthobranchia). Trans. Zool. Soc. Lond. 34, 45-86 (1977).

37. Wägele, H. Rasterelektronenmikroskopische Untersuchungen an Radulae einiger Nordseeschnecken (Gastropoda: Prosobranchia) mit Anmerkungen zur Funktionsmorphologie. Drosera. 83 (1), 68-78 (1983).

38. Hawkins, S. J. et al. A comparison of feeding mechanisms in microphagous, herbivorous, intertidal, prosobranchs in relation to resource partitioning. J. Molluscan Stud. 55 (2), 151-165 (1989). 
39. Scheel, C., Gorb, S. N., Glaubrecht, M. \& Krings, W. 2020. Not just scratching the surface: Distinct radular motion patterns in Molluscan taxa. Biology Open, bio.055699.

40. Solem, A. Patterns of radular tooth structure in carnivorous land snails. Veliger. 17, 81-88 (1974).

41. Walsby, J. R. Feeding and the radula in the marine pulmonate limpet, Trimusculus reticulatus. Veliger. 18, 139-145 (1975).

42. Jensen, K. R. A review of sacoglossan diets, with comparative notes on radular and buccal anatomy. Malacological Review. 13, 55-77 (1980).

43. Jensen, K. R. Observations on feeding methods in some Florida ascoglossans. J. Molluscan Stud. 47 (2), 190-199 (1981).

44. Jensen, K. R. Factor affecting feeding selectivity in herbivorous Ascoglossa (Mollusca: Opisthobranchia). J. Exp. Mar. Biol. Ecol. 66 (2), 135-148 (1983).

45. Jensen, K. R. Morphological adaptations and plasticity of radular teeth of the Sacoglossa (= Ascoglossa) (Mollusca: Opisthobranchia) in relation to their food plants. Biol. J. Linn. Soc. 48 (2), 135-155 (1993).

46. Jensen, K. R. Evolution of the Sacoglossa (Mollusca, Opisthobranchia) and the ecological associations with their food plants. Evol. Ecol. 11, 301-335 (1997).

47. Steneck, R. S. \& Watling, L. Feeding capabilities and limitation of herbivorous molluscs: a functional group approach. Mar. Biol. 68, 299-319 (1982).

48. Burch, J. B. \& Jeong, K. H. The radula teeth of selected Planorbidae. Malacological Review. 17 (1-2), 67-84 (1984).

49. Kesler, D. H., Jokinen, E. H. \& Munns, W. R. Jr. Trophic preferences and feeding morphology of two pulmonate snail species from a small New England pond, USA. Can. J. Zool. 64 (11), 2570-2575 (1986).

50. Black, R., Lymbery, A. \& Hill, A. Form and function: size of radular teeth and inorganic content of faeces in a guild of grazing molluscs at Rottnest Island, Western Australia. J. Exp. Mar. Biol. Ecol. 121, 23-35 (1988).

51. Nishi, M. \& Kohn, A. J. Radular teeth of Indo-Pacific molluscivorous species of Conus: a comparative analysis. J. Mollus. Stud. 65, 483-497 (1999).

52. Duda, T. F., Kohn, A. J. \& Palumbi, S. R. Origins of diverse feeding ecologies within Conus, a genus of venomous marine gastropods. Biol. J. Linn. Soc. 73, 391-409 (2001).

53. Rintelen, T., Wilson, A. B., Meyer, A. \& Glaubrecht, M. 2004. Escalation and trophic specialization drive adaptive radiation of freshwater gastropods in ancient lakes on Sulawesi, Indonesia. Proc. R. Soc. Lond. 271(1557), 2541-2549.

54. Ramesh, R. \& Ravichandran, S. Feeding biology with reference to algal preference and scanning electron microscopy studies on the radula of Turbo brunneus. Trends Appl. Sci. Res. 3 (2), 189-195 (2008). 
55. Krings, W., Brütt, J. O., Gorb, S. N. \& Glaubrecht, M. Tightening it up: Diversity of the chitin anchorage of radular teeth in paludomid freshwater-gastropods. Malacologia. 63 (1), 77-94 (2020a).

56. Bleakney, J. S. Indirect evidence of a morphological response in the radula of Placida dentritica (Alder and Hancock, 1843) (Opisthobranchia, Ascoglossa/ Sacoglossa) to different algae prey. Veliger. 33 (1), 111-115 (1990).

57. Padilla, D. K., Dilger, E. K. \& Dittmann, D. E. Phenotypic plasticity of feeding structures in species of Littorina. Am. Zool. 40 (6), 1161-1161 (2000).

58. Padilla, D. K., Dittman, D. E., Franz, J. \& Sladek, R. Radula production rates in two species of Lacuna Turton (Gastropoda: Littorinidae). J. Molluscan Stud. 62, 275-280 (1996).

59. Padilla, D. K. Inducible phenotypic plasticity of the radula in Lacuna (Gastropoda: Littorinidae). Veliger. 41 (2), 201-204 (1998).

60. Padilla, D. K. Food and environmental cues trigger an inducible offense. Evol. Ecol. Res. 3, 15-25 (2001).

61. Reid, D. G. \& Mak, Y. M. Indirect evidence for ecophenotypic plasticity in radular dentition of Littoraria species (Gastropoda: Littorinidae). J. Moll. Stud. 65 (3), 355-370 (1999).

62. Trussell, G. C. Phenotypic clines, plasticity, and morphological trade-offs in an intertidal snail. Evolution. 54 (1), 151-166 (2000).

63. Ito, A., Ilano, A. S. \& Nakao, S. Seasonal and tidal height variations in body weight and radular length in Nodilittorina radiate (Eydoux and Souleyet, 1852). J. Mollus. Stud. 68 (3), 197-203 (2002).

64. Andrade, S. C. S. \& Solferini, V. N. The influence of size on the radula of Littoraria angulifera (Gastropoda: Littorinidae). Malacologica. 49 (1), 1-5 (2006).

65. Grünbaum, D. \& Padilla, D. K. An integrated modeling approach to assessing linkages between environment, organism, and phenotypic plasticity. Integr. Comp. Biol. 54 (2), 323-335 (2014).

66. Molis, M., Scrosati, R. A., El-Belely, E. F., Lesniowski, T. J. \& Wahl, M. Wave-induced changes in seaweed toughness entail plastic modifications in snail traits maintaining consumption efficacy. $J$. Ecol. 103 (4), 851-859 (2015).

67. Breure, A. S. H. \& Gittenberger, E. The rock-scraping radula, a striking case of convergence (Mollusca). Neth. J. Zool. 32, 307-312 (1981).

68. Weaver, J. C. et al. Analysis of an ultra hard magnetic biomineral in chiton radular teeth. Mater. Today. 13, 42-52 (2010).

69. Lu, D. \& Barber, A. H. Optimized nanoscale composite behaviour in limpet teeth. J. Royal Soc. Interface. 9, 1318-1324 (2012).

70. Grunenfelder, L. K. et al. Biomineralization: Stress and damage mitigation from oriented nanostructures within the radular teeth of Cryptochiton stelleri. Adv. Funct. Mater. 24/39, 6085 (2014).

71. Barber, A. H., Lu, D. \& Pugno, N. M. Extreme strength observed in limpet teeth. J. Roy Soc. Interface. 12, 20141326 (2015). 
72. Ukmar-Godec, T. et al. Materials nanoarchitecturing via cation-mediated protein assembly: Making limpet teeth without mineral. Adv. Mater. 29, 1701171 (2017).

73. Ukmar-Godec, T., Kapun, G., Zaslansky, P. \& Faivre, D. The giant keyhole limpet radular teeth: A naturally-grown harvest machine. J. Struct. Biol. 192 (3), 392-402 (2015).

74. Krings, W., Kovalev, A., Glaubrecht, M. \& Gorb, S. N. Differences in the Young modulus and hardness reflect different functions of teeth within the taenioglossan radula of gastropods. Zoology. 137, 125713 (2019b).

75. Krings, W., Marcé-Nogué, N., Karabacak, H., Glaubrecht, M. \& Gorb, S. N. Finite element analysis of individual taenioglossan radula teeth. Acta Biomater. 115 (1), 317-332 (2020b).

76. Hayes, T. The influence of diet on local distributions of Cypraea. Pac. Sci. 37 (1), 27-36 (1983).

77. Padilla, D. K. The importance of form: Differences in competitive ability, resistance to consumers and environmental stress in an assemblage of coralline algae. J. Exp. Mar. Biol. Ecol. 79 (2), 105-127 (1984).

78. Blinn, W., Truitt, R. E. \& Pickart, A. 1989. Feeding ecology and radular morphology of the freshwater limpet Ferrissia fragilis.J. N. Am. Benthol. Soc.237-242.

79. Franz, C. J. Feeding patterns of Fissurella species on Isla de Margarita, Venezuela: use of radulae and food passage rates. J. Mollus. Stud. 56, 25-35 (1990).

80. Thompson, R. C., Johnson, L. E. \& Hawkins, S. J. A method for spatial and temporal assessment of gastropod grazing intensity in the field: the use of radula scrapes on wax surfaces. J. Exp. Mar. Biol. Ecol. 218 (1), 63-76 (1997).

81. Iken, K. 1999. Feeding ecology of the Antarctic herbivorous gastropod Laevilacunaria antarctica Martens. J. Exp. Mar. Biol. Ecol. 236(1), 133 - 48.

82. Forrest, R. E., Chapman, M. G. \& Underwood, A. J. Quantification of radular marks as a method for estimating grazing of intertidal gastropods on rocky shores. J. Exp. Mar. Biol. Ecol. 258 (2), 155-171 (2001).

83. Dimitriadis, V. K., 2001. Structure and function of the digestive system in Stylommatophora. In: Barker, G.M. (Ed.). The Biology of Terrestrial Molluscs,p. 237-258.CABI Publishing, Wallingford, UK.

84. Speiser, B., 2001. Food and feeding behaviour. In: Barker, G.M. (Ed.). The Biology of Terrestrial Molluscs,p. 259-288.CABI Publishing, Wallingford, UK.

85. Sutton, G. P. et al. Neural control exploits changing mechanical advantage and context dependence to generate different feeding responses in Aplysia. Biol. Cybern. 91, 333-345 (2004).

86. Mangan, E. V. et al. A biologically inspired gripping device. Ind. Rob. 32, 49-54 (2005).

87. Padilla, D. K. Structural resistance of algae to herbivores. A biomechanical approach. Mar. Biol. 90, 103-109 (1985).

88. Padilla, D. K. Algal structural defenses: form and calcification in resistance to tropical limpets. Ecology. 70 (4), 835-842 (1989). 
89. Krings, W. et al. In slow motion: radula motion pattern and forces exerted to the substrate in the land snail Cornu aspersum (Mollusca, Gastropoda) during feeding. R. Soc. Open Sci. 6, 190222 (2019a).

90. Mackenstedt, U. \& Märkel, K., 2001. Radula structure and function. In: Barker, G.M. (Ed.). The Biology of Terrestrial Molluscs,p. 213-236.CABI Publishing, Wallingford, UK.

91. Neustadter, D. M., Drushel, R. F. \& Chiel, H. J. Kinematics of the buccal mass during swallowing based on magnetic resonance imaging in intact, behaving Aplysia californica. J. Exp. Biol. 205, 939-958 (2002b).

92. Neustadter, D. M., Drushel, R. F., Crago, P. E., Adams, B. W. \& Chiel, H. J. A kinematic model of swallowing in Aplysia californica based on radula/odontophore kinematics and in vivo magnetic resonance images. J. Exp. Biol. 205, 3177-3206 (2002a).

93. Neustadter, D. M., Drushel, R. F., Crago, P. E. \& Chiel, H. J. A 3-dimensional model of the odontophore of Aplysia throughout a swallowing cycle. Soc. Neurosci. Abstr. 27, 9437 (2001).

94. Kehl, C. E. et al. Soft-surface grasping: radular opening in Alysia californica. J. Exp. Biol. 222, jeb191254 (2019).

95. Montroni, D. et al. Structural characterization of the buccal mass of Ariolimax californicus (Gastropoda; Stylommatophora). PLoS ONE. 14 (8), (2019). e0212249

96. Holznagel, W. A nondestructive method for cleaning gastropod radulae from frozen, alcohol-fixed, or dried material. Am. Malacol. Bull. 14 (2), 181-183 (1998).

97. Wakeling, J. M., Kemp, K. M. \& Johnston, I. A. The biomechanics of fast-starts during ontogeny in the common carp (Cyprinus carpio). J. Exp. Biol. 202, 3057-3067 (1999).

98. Hutchinson, J. R. \& Garcia, M. Tyrannosaurus was not a fast runner. Nature. 415, 1018-1021 (2002).

99. Alexander, R. M. The maximum forces exerted by animals. J. Exp. Biol. 115, 231-238 (1985).

100. Heethoff, M. \& Norton, R. A. A new use for synchrotron X-ray microtomography: three-dimensional biomechanical modeling of chelicerate mouthparts and calculation of theoretical bite forces. Invertebr. Biol. 128, 332-339 (2009).

101. Sakamoto, M., Lloyd, G. T. \& Benton, M. J. Phylogenetically structured variance in felid bite force: the role of phylogeny in the evolution of biting performance. J. Evol. Biol. 23, 463-478 (2010).

102. Sakamoto, M., Ruta, M. \& Venditti, C. 2019. Extreme and rapid bursts of functional adaptions shape bite force in amniotes. Proc. R. Soc. B. 286, 20181932.

103. Vogel, S. Comparative Biomechanics. Life's Physical World second edn320 pp(Princeton University Press, Princeton, New Jersey, 2013).

104. Alexander, D. E. Nature's Machines. An Introduction to Organismal Biomechanics189 pp(Academic Press, London, UK, 2017).

105. Pfaller, J. B., Gignac, P. M. \& Erickson, G. M. Ontogenetic changes in jaw-muscle architecture facilitate durophagy in the turtle Sternotherus minor. J. Exp. Biol. 214, 1655-1667 (2010).

106. Becerra, F., Echeverria, A. I., Casinos, A. \& Vassallo, A. I. Another one bites the dust: Bite force and ecology in three caviomorph rodents (Rodentia, Hystricognathi). J. Exp. Zool. 321A, 220-232 (2014). 
107. Chapman, R. F., 1995. Mechanics of food handling by chewing insects. In: Chapman, R.F., de Boer, G. (Ed.). Regulatory Mechanisms in Insect Feeding,p. 3-31.Springer Science + Business Media Dordrecht, Berlin.

108. Chiel, H. J. Aplysia feeding biomechanics. Scholarpedia. 2 (9), 4165 (2007).

109. Van der Meij, M. A. A. \& Bout, R. G. The relationship between shape of the skull and bite force in finches. J. Exp. Biol. 211, 1668-1680 (2008).

110. Marshall, C. D. et al. The ontogenetic scaling of bite force and head size in loggerhead sea turtles (Caretta caretta): implications for durophagy in neretic, benthic habitats. J. Exp. Biol. 215, 41664174 (2012).

111. Forbes-Harper, J. L. et al. Diet and bite force in red foxes: ontogenetic and sex difference in an invasive carnivore. J. Zool. 303 (1), 54-63 (2017).

112. Ahn, A. N. \& Full, R. J. A motor and a brake: two leg extensor muscles acting at the same joint manage energy differently in a running insect. J. Exp. Biol. 205, 379-389 (2002).

113. Guschlbauer, C., Scharstein, H. \& Buschges, A. The extensor tibiae muscle of the stick insect: biomechanical properties of an insect walking leg muscle. J. Exp. Biol. 210, 1092-1108 (2007).

114. Siebert, T., Weihmann, T., Rode, C. \& Blickhan, R. Cupiennius salei: biomechanical properties of the tibia-metatarsus joint and its flexing muscles. J. Comp. Physiol. B. 180, 199-209 (2010).

115. Reingold, S. C. \& Gelperin, A. Feeding motor programme in Limax. II. Modulation by sensory inputs in intact animals and isolated central nervous systems. J. Exp. Biol. 85, 1-20 (1980).

116. Hurwitz, I. \& Susswein, A. J. Adaptation of feeding sequences in Aplysia oculifera to changes in the load and width of food. J. Exp. Biol. 166, 215-235 (1992).

117. Kupfermann, I. Feeding in Aplysia: A simple system for the study of motivation. Behav. Biol. 10, 1-26 (1974).

118. Susswein, A. J. \& Bennett, M. V. L. Plasticity of feeding behavior in the opisthobranch mollusc Navanax. J. Neurobiol. 10, 521-534 (1979).

119. Susswein, A. J., Achituv, Y., Cappell, M. C. \& Bennett, M. V. L. Pharyngeal movements during feeding sequences in Navanax inermis: a cinematographic analysis. J. Comp. Physiol. A. 155, 209-218 (1984).

120. Pennings, S. C. Size-related shifts in herbivory: specialization in the sea hare Aplysia californica Cooper. J. Exp. Mar. Biol. Ecol. 142, 43-61 (1990).

\section{Figures}




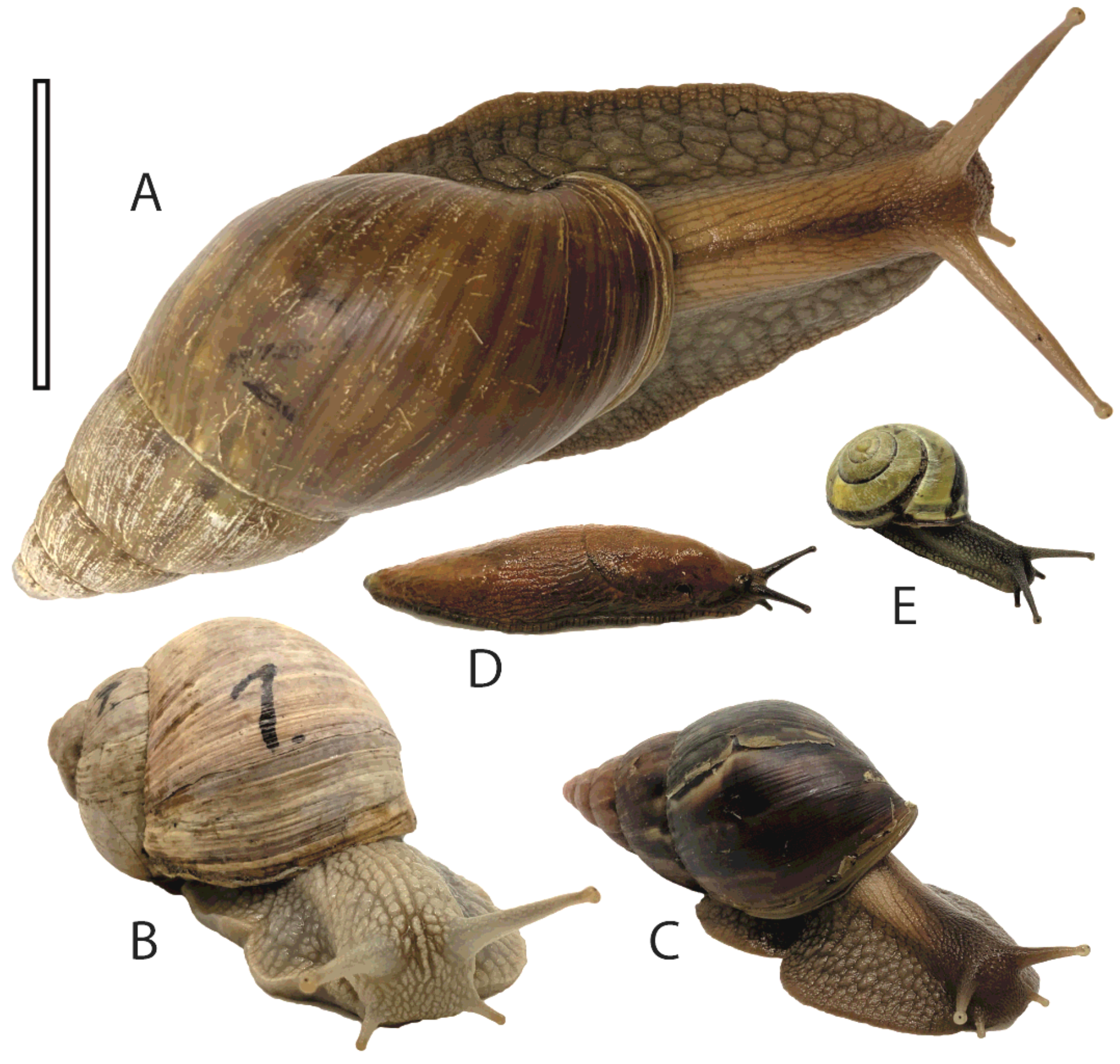

Figure 1

Mollusc species used in this study. A. Mature Lissachatina fulica. B. Helix pomatia. C. Immature Lissachatina fulica. D. Arion vulgaris. E. Cepaea nemoralis. Scale bar $=4 \mathrm{~cm}$. 


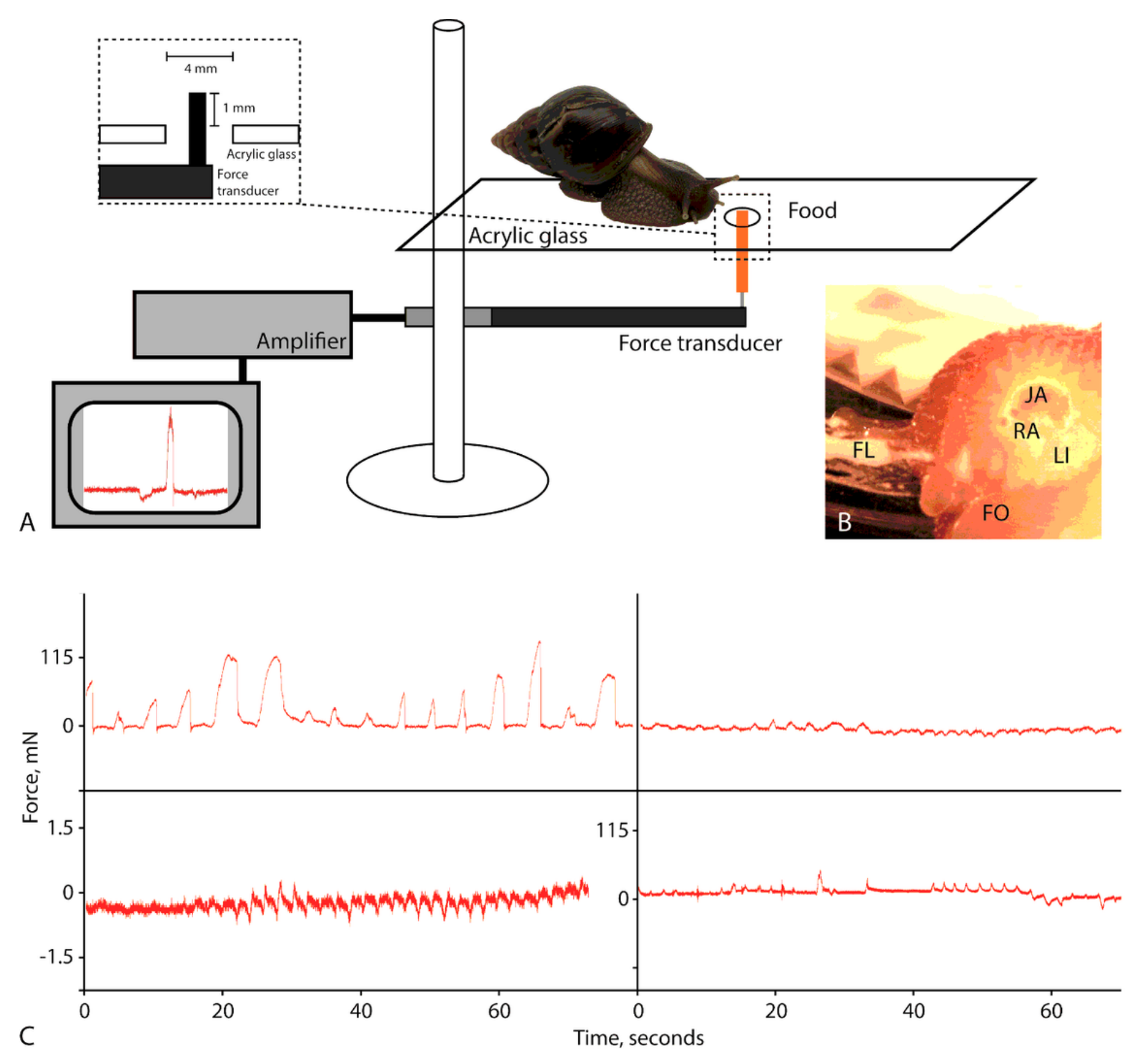

Figure 2

Experimental set-up [modified from 89] and characteristic radular force measurements. A. Gastropods were placed on an acrylic platform with a hole of $2 \mathrm{~mm}$ diameter. The sliced food (e.g. carrot), glued to a needle, was firmly mounted to a force transducer connected with an amplifier and computer-based data acquisition and processing system. The food was stuck through the hole, so that animals could feed on it without involving their foot. B. Image of the mouth opening taken through the glass platform. C. Characteristic radular force measurement curves, $\mathrm{mN}$, of mature Lissachatina fulica, (above) and Arion vulgaris (below); left side: vertical direction (positive peaks = pulling up, negative peaks = pushing down), right side: horizontal direction (positive peaks = posterior direction, negative peaks $=$ anterior direction). $J A=$ jaw, $F L=$ flour, $F O=$ foot, $\mathrm{LI}=$ lip, $R A=$ radula. 


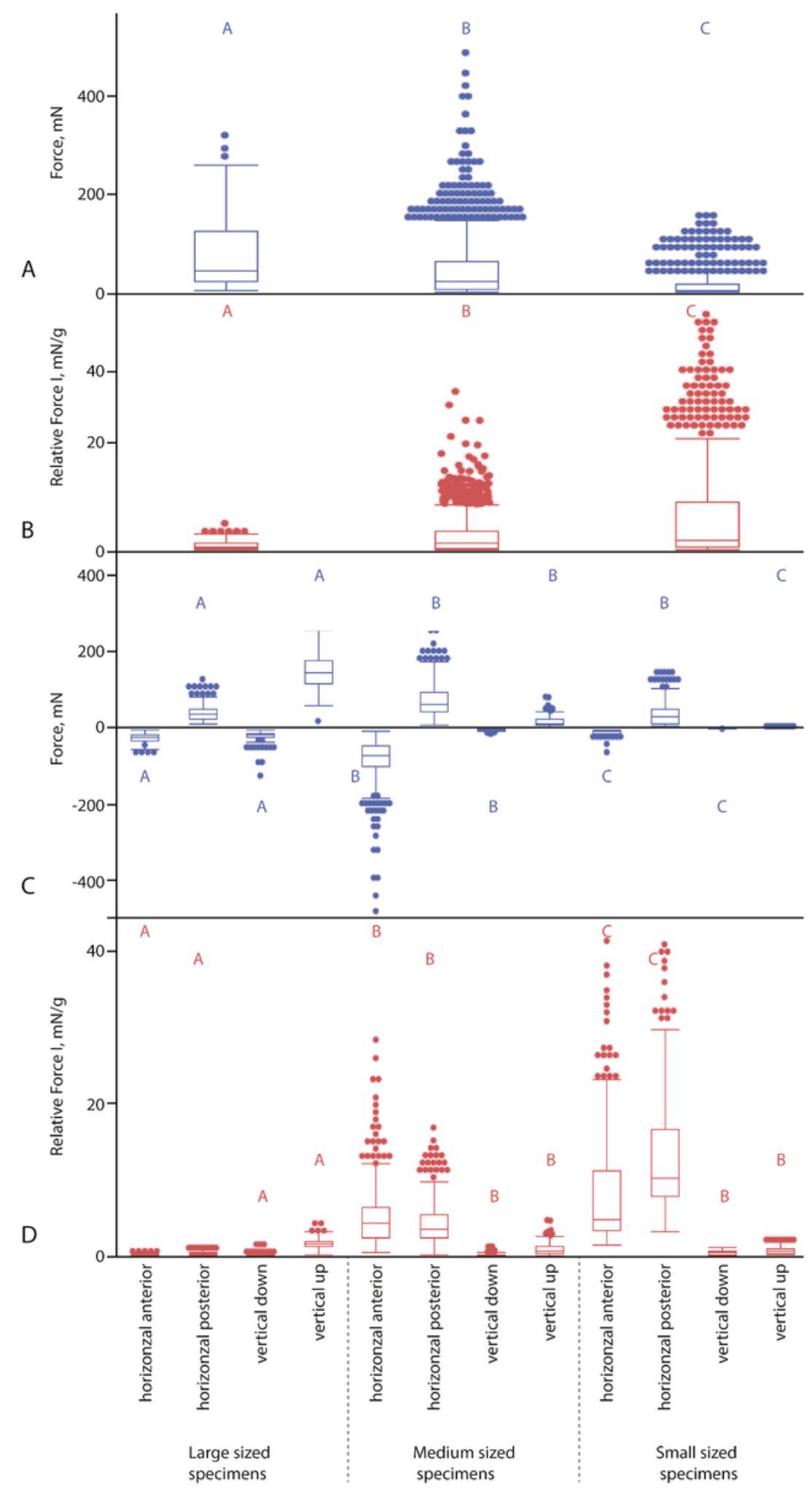

Figure 3

Absolute Force and Relative Force I for distinct body mass classes (large-, medium-, and small-sized gastropods). A. Absolute Force (regardless to the direction of measurement). B. Relative Force I (regardless to the direction of measurement). C. Absolute Force assorted to directions. D. Relative Force I assorted to directions. Letters are connecting letters from the Tukey-Kramer test and identify homogenous groups (letters at same height depicts which groups are statistically compared). 


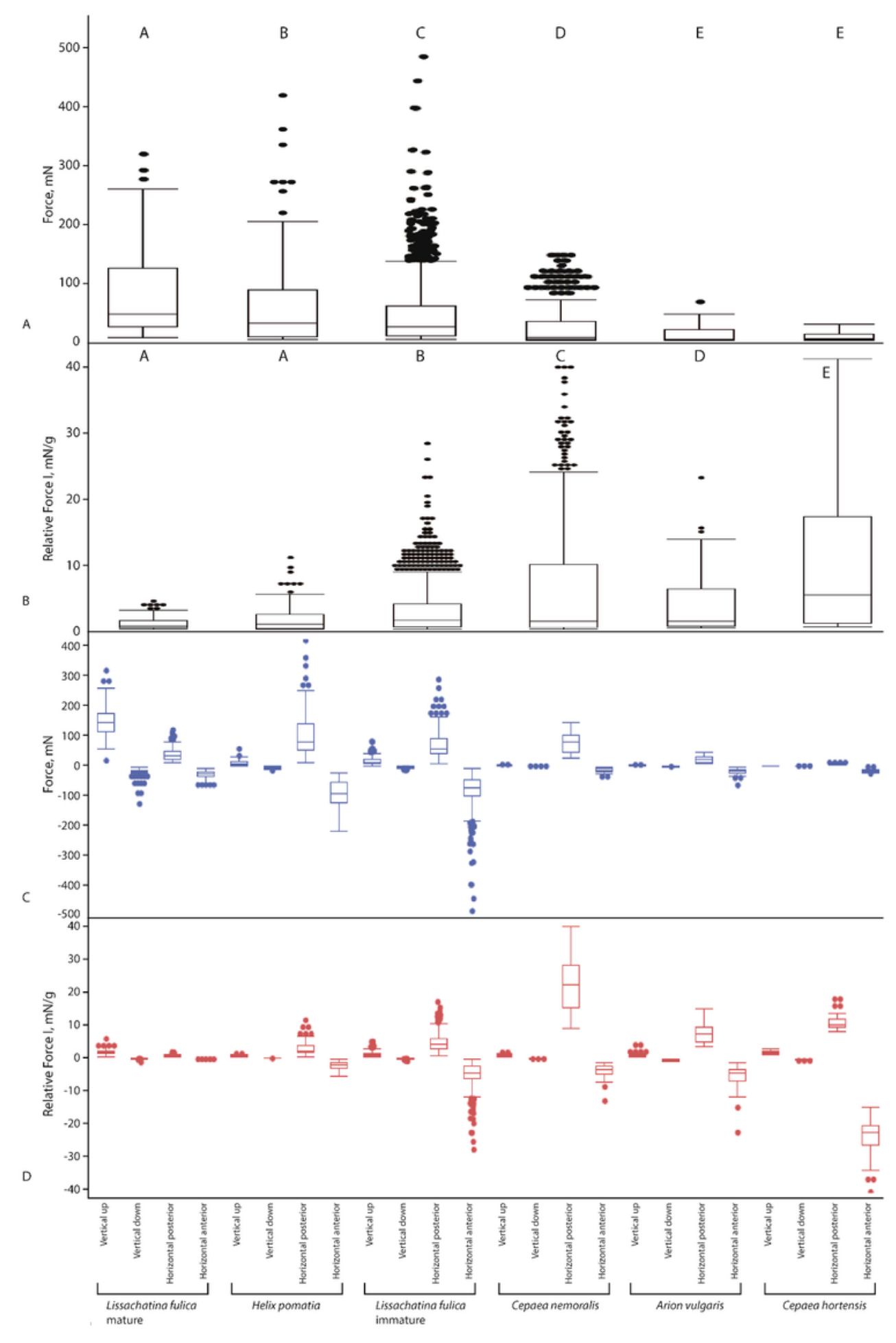

Figure 4

Absolute Force and Relative Force I for distinct cohorts. A. Absolute Force (regardless to the direction of measurement), letters are connecting letters from Tukey-Kramer test. B. Relative Force I (regardless to the direction of measurement), letters are connecting letters from Tukey-Kramer test. C. Absolute Force assorted to directions. D. Relative Force I assorted to directions. For values and connecting letters from the Tukey-Kramer test of C and D see Supplementary Tab. 2. 

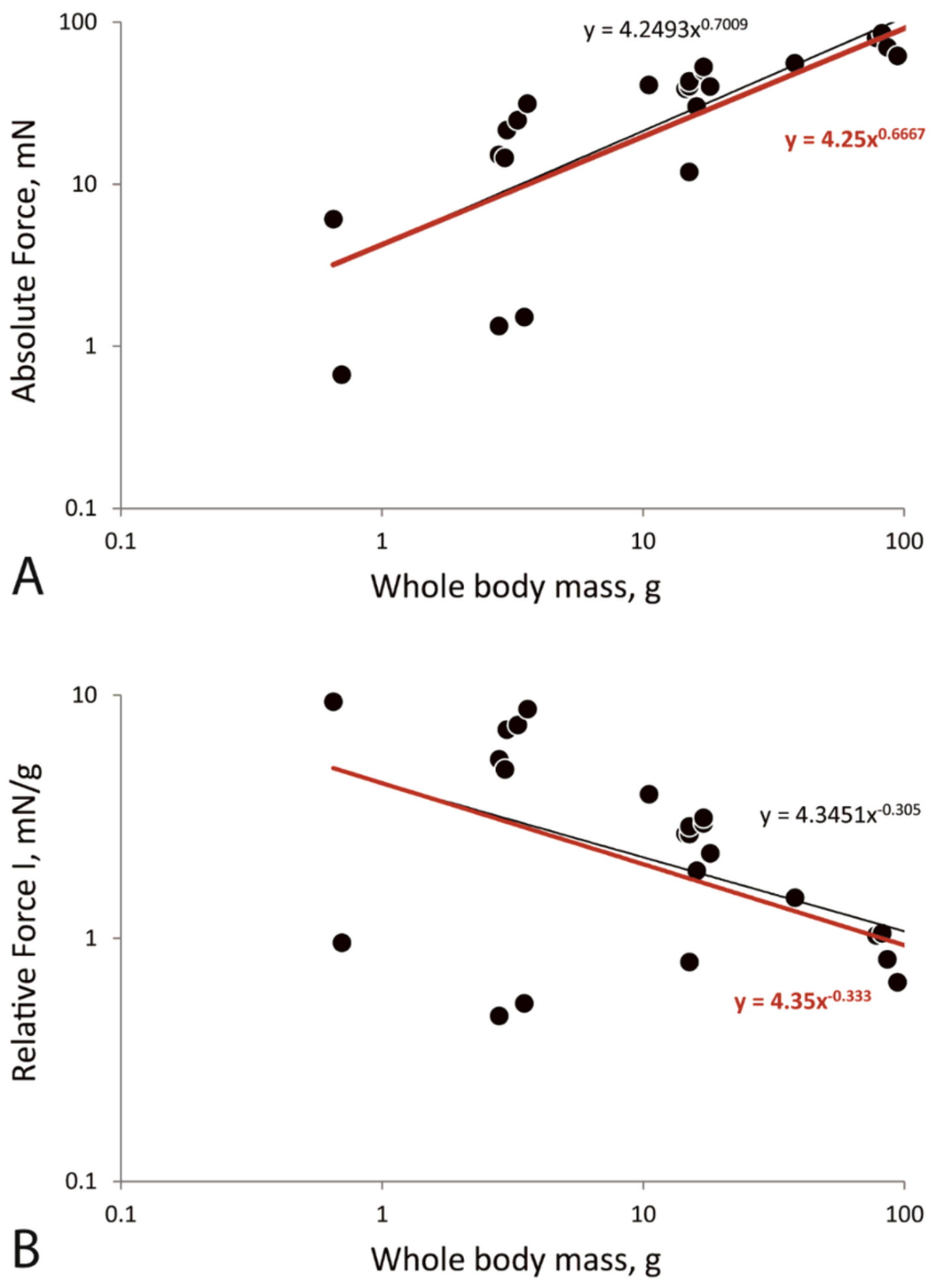

Figure 5

Linear regression, displayed on logarithmic axes, with trend line of A. Absolute Force mean versus whole body mass mean. A radular force quotient, $A F Q=a b s o l u t e f o r c e /$ bodymass 0.67 , of 4.25 was determined; and $B$. Relative Force I mean versus whole body mass mean. A relative force quotient, $\mathrm{RFQ}=$ relativeforcel/bodymass- 0.33 , of 4.35 was determined. 


\section{Supplementary Files}

This is a list of supplementary files associated with this preprint. Click to download.

- Supplementsscientificreports.pdf 